\title{
Research on the Internal Control of Commercial Banks Based on Five Elements of COSO-Take Shanghai Pudong Development Bank as an Example
}

Jingni Jia ${ }^{1 *}$, Taotao Wang ${ }^{2}$

${ }^{1}$ School of Accounting, Anhui University of Finance and Economics, Bengbu 233030 Anhui, China. E-mail: jjn991220@163.com

${ }^{2}$ School of Finance, Anhui University of Finance and Economics, Bengbu 233030, Anhui, China

Abstract: With the rapid development of economy, the business volume of China's commercial banks is increasing day by day. At the same time, the internal control problems of commercial banks have also been highlighted in the frequent violations of commercial banks in recent years, and many commercial banks have been punished successively. In order to continuously improve the internal control level of China's commercial banks and reduce the incidence of banking violations, this paper analyzes the internal control of Shanghai Pudong Development Bank (SPDB) based on the five elements of COSO internal control framework, and explores some problems existing in the internal control of China's commercial banks, and analyzes the internal control of commercial banks from different aspects. Targeted measures and suggestions for the control system are also put forward.

Keywords: Commercial Bank; COSO Five Elements; Internal Control; Risk Management

\section{Introduction}

As one of commercial bank giants in China, Pudong Development Bank Chengdu Branch was fined 462 million yuan for illegal lending in 2018, which is a major violation case in the financial market. This incident has aroused the concern of China Banking Regulatory Commission and other national departments on the internal control of commercial banks in China, and Shanghai Pudong Development Bank has further improved its internal control system. However, since 2019, Shanghai Pudong Development Bank and its branches and individuals have received at least 56 penalty tickets. The main illegal facts include converting loan funds into deposits, misappropriating credit funds in violation of regulations, careless management of seal use, split credit, and ultra vires approval. It can be seen that although the relevant departments of the state strictly rectify the disorder of commercial banks and commercial banks themselves are constantly improving the internal control system, there are still great problems in the internal control and risk management of China's commercial banks ${ }^{[1]}$.

\section{Basic information of Shanghai Pudong Development Bank}

Shanghai Pudong Development Bank was established with the approval of the People's Bank of China in 1992. It is one of the representative commercial banks in China. Facing the increasingly competitive financial market, Shanghai Pudong Development Bank (SPDB) has been speeding up the pace of internationalization and comprehensive operation,

Copyright (C) 2020 Jingni Jia et al.

doi: $10.18686 /$ aat.v2i3.1332

This is an open-access article distributed under the terms of the Creative Commons Attribution Non-Commercial License

(http://creativecommons.org/licenses/by-nc/4.0/), which permits unrestricted non-commercial use, distribution, and reproduction in any medium,

provided the original work is properly cited. 
and its world rankings have been continuously improved. When Shanghai Pudong Development Bank was initially established, its total assets reached 8.75 billion yuan. By June 2018, the total assets had reached 6091.759 billion yuan with a rapid growth rate of 696 times, and its annual average compound growth rate of net profit was as high as $30 \%$. However, various problems caused by the rapid development have become increasingly prominent, and its internal control system cannot adapt to the continuous expansion of the scale.

\section{Internal control analysis based on COSO five elements}

\subsection{Control of environment analysis}

Firstly, there are problems existing in the management purpose and operation mode of the branch. Taking the Chengdu Branch of Shanghai Pudong Development Bank as an example, its management tenet has seriously deviated from the purpose of the head office. It excessively pursues the ranking of performance appraisal in the head office. In order to improve the performance, it does not hesitate to take improper means such as whitewashing statements and increasing profits, which leads to a serious lack of internal control culture. Secondly, the branch examination and approval center is in vain. In order to strengthen the effective control of credit approval risk, Shanghai Pudong Development Bank has established a branch centralized approval center. However, in the process of illegally issuing loans and misappropriating non-performing assets in Chengdu Branch, the branch approval center did not play its role, which shows that there are defects in its institutional arrangement, organizational structure and division of powers and responsibilities at the sub branch level. Thirdly, the concept of internal staff integrity is weak. The financial report shows that the non-performing loan rate of Chengdu Branch is zero. In order to achieve this goal successfully, we need the cooperation of internal grass-roots operators and senior managers. Therefore, the internal staff of Shanghai Pudong Development Bank are lack of integrity awareness.

\subsection{Information and communication analysis}

The reasons are as follows: firstly, the credit information identification system has not been established. The credit information of Shanghai Pudong Development Bank is still manually entered by the staff in charge of credit, and there is no information identification system to effectively verify and identify the authenticity and integrity of credit information. Therefore, credit officers can easily enter false information into the management system, thus causing losses to the bank $^{[2]}$. Secondly, credit information cannot be completely entered. Shanghai Pudong Development Bank for the borrower's industry development trend, the borrower's background information and other information can not be guaranteed to be completely stored in the information management system; in addition, SPDB does not dynamically track the development and management status of credit investment projects through various effective ways many times. To a great extent, this will affect the timely and effective transmission of credit information.

\subsection{Supervision and analysis}

Firstly, internal audit lacks independence. The Audit Department of Chengdu Branch of Shanghai Pudong Development Bank has a parallel relationship with other business departments. It is not independent of other business departments, nor has it set up a special board of supervisors or audit committee to be directly responsible for the audit work. Its internal audit and internal control management are directly responsible by the high-level leaders headed by the president. The internal audit responsibilities are not clear enough and only pay attention to the afterwards audit review, which ignores the prior and in-process guidance and supervision. Secondly, the efficiency of supervision activities is low. The post loan management in the process of credit extension is a key link in the process of bank credit risk management. The serious lack of this aspect is an important reason for the occurrence of large amount of non-performing loans in Shanghai Pudong Development Bank, and the audit system has not played an important role. Under various pressures, auditors make the supervision work a mere formality.

\subsection{Control of activity analysis}


Firstly, the system of job rotation can not be implemented seriously. The job rotation system of key positions is an important system for commercial banks to prevent risks, which can improve the mobility of employees in key positions and reduce operational risk. Taking Chengdu Branch as an example, its leaders have held important management posts for ten years. This situation is easy to make the internal control and risk management of the bank affected by personal risk management attitude and management style, and the internal risk gradually accumulated. Secondly, there are problems in the internal assessment and incentive system ${ }^{[3]}$. In order to continue to maintain the past excellent performance, the internal staff ignore the internal control system and blindly pursue performance improvement. Thirdly, credit splitting and ultra vires approval. In order to cover up non-performing loans and increase performance by planned arrangement of credit splitting and ultra vires approval, the principle of authorization control in internal control of commercial banks is seriously ignored.

\subsection{Risk assessment and analysis}

Risk identification under COSO framework emphasizes not only the identified risks, but also the new risks. In the process of risk identification, bank management should not only identify the risks within the scope of business, but also clarify the importance of risks according to the probability and time of risk occurrence ${ }^{[4]}$. Under normal circumstances, commercial banks will certainly have non-performing loans, but the abnormal situation of "zero non-performing loans" in Chengdu Branch has not attracted the attention of the head office, risk control, audit and other relevant departments for a long time. As a potential risk event, it has not been identified in time.

\section{Reasons for problems in internal control of Shanghai Pudong Develop- ment Bank}

According to the analysis of the internal control problems of Shanghai Pudong Development Bank based on COSO five elements, it is not difficult to summarize the main reasons for the internal control problems of Shanghai Pudong Development Bank as follows: firstly, the internal control environment of Shanghai Pudong Development Bank is not good, which is mainly manifested in the following aspects: the professional quality and moral quality of employees need to be improved; the management thought is "business is more important than management"; the division of responsibilities of departments is not clear. Secondly, the evaluation method of internal control management is backward, the quality of risk assessment is low and the effectiveness is weak, and these mainly manifested in the lag of internal control evaluation index system and the lack of full use of advanced scientific and technological means in internal control monitoring. Thirdly, the execution of its internal control activities is weak due to the staff's weak compliance awareness, the bank's training is not in place, and its internal accountability is not rigorous and strict. Fourthly, its information exchange and supervision and evaluation mechanism are not perfect, which greatly affects the effect of its internal control. Through the analysis and summary of the internal control problems of Shanghai Pudong Development Bank, we can put forward optimization suggestions for the internal control of commercial banks.

\section{Measures to improve the internal control of commercial banks}

\subsection{Improvement of employees' awareness of risk prevention and control and moral concept}

At present, the overall education level of commercial bank employees has been greatly improved, and their professional skills are relatively complete, but the moral quality and risk prevention awareness of some employees still need to be improved. In order to improve the risk control environment of commercial banks, the first is to improve the awareness of risk prevention and control from grass-roots operators to bank management, so that risk control runs through all aspects of the bank's operation. Commercial banks should, according to the specific work tasks of employees, carry out targeted training on the types of risks that may exist in the work process and the corresponding measures, so as to improve the risk awareness of employees in different businesses. Next, it is necessary to improve the moral concept of commercial bank employees, especially the integrity awareness of bank accountants and credit personnel. 
Commercial banks should regularly carry out moral education for their employees based on their actual situation. Through some educational activities, they can imperceptibly improve their moral quality after entertainment, so that they can consciously abide by professional ethics in their daily activities ${ }^{[5]}$.

\subsection{Improvement of the internal control system of commercial banks}

The sound internal control system of commercial banks is a key to strengthen the internal control of cial banks, which can effectively prevent and reduce the possible violations in the operation process of cial banks. Among them, we can improve the internal control system of commercial banks by improving the internal distribution incentive system, conscientiously implementing the job rotation system, and constructing the responsible person system and decision-making constraint system.

(1) Improve the distribution incentive system. The first is the compatibility of constraint and incentive. It is necessary to design the internal income distribution system of commercial banks in order to motivate employees and improve the interests of owners, so as to maximize the income of employees and banks, reduce internal conflicts and risks.

(2) Conscientiously implement the shift system. The rotation system of important positions in banks can avoid the employees' control over a certain business to a certain extent, and can effectively reduce the influence of important management on the internal control of the bank. It has a supervisory and professional role on the rights of the main business leaders and decision makers, and forms a mutual supervision mechanism within the bank to a certain extent.

(3) We should construct the system of responsible person and decision-making restriction system ${ }^{[6]}$. On the one hand, it can improve the implementation efficiency and efficiency of major issues, on the other hand, it can improve the rationality and scientificity of decision-making, avoid the control of major decisions by one person, and effectively reduce the decision-making risk and implementation risk.

\subsection{Strengthening the quality of risk assessment of commercial banks}

As another important part of the internal control process of commercial banks, risk assessment plays a direct role in whether the various risks existing in commercial banks can be discovered in time, and the results of risk assessment will directly affect the response measures of commercial banks to risks. Therefore, on the one hand, commercial banks should improve the risk assessment system, increase quantitative assessment and reduce qualitative assessment, so as to reduce the impact of subjective judgment. The scope of risk assessment should cover all business areas of the bank and all possible risk types, and take timely and effective response measures to reduce or avoid the losses caused by risks. On the other hand, it is necessary to improve the professional skills of risk assessment personnel, so that they have the accuracy of risk assessment and the ability to control the existing risks ${ }^{[7]}$.

\subsection{Strengthening external supervision}

To improve the internal control of commercial banks, we should not only start from the commercial banks themselves, but also need the joint supervision of relevant national departments and all sectors of society ${ }^{[8]}$. For the relevant departments of the state, we should formulate and improve the internal control standard system of commercial banks, form a set of unified internal control evaluation standards for commercial banks, and strictly supervise and inspect the rationality, effectiveness and soundness of internal control of commercial banks. Facing the violations found in the review, we should not only increase the intensity of punishment, but also urge them to fundamentally rectify and eliminate the recurrence of the problem. For the society, the public should report the illegal behaviors of commercial banks to the relevant departments in time, and other financial institutions in the industry should also supervise each other.

\section{Conclusion}

In the rapid development of commercial banks, in order to pursue business performance and profits, there are often problems in their internal control, such as incomplete and untrue business information, inadequate information commu- 
nication, lack of independence of internal audit, low efficiency of supervision activities and loopholes in internal control system. In order to improve the internal control of commercial banks, commercial banks should improve their staff's awareness of risk prevention and control and moral concepts, improve the internal control system and the quality of risk assessment. At the same time, it should also strengthen the external supervision of commercial banks, standardize relevant laws and regulations, and increase punishment for violations of financial market.

\section{References}

1. Zhang Q. Research on risk oriented internal control mode of commercial banks (in Chinese). Financial Circles (Academic Edition) 2019; (18): 90.

2. Zhou X. Research on accounting risk management of X city and county sub branches of Agricultural Development Bank [MSc thesis] (in Chinese). Taiyuan: Taiyuan University of Technology; 2019.

3. Lu S. Research on internal control optimization of Abbott based on COSO framework [MSc thesis] (in Chinese). Jilin: Jilin University; 2019.

4. Zhou H. Research on internal control of commercial banks in China [MSc thesis] (in Chinese). Harbin: Northeast Forestry University; 2003.

5. Zhang L. Research on internal control problems and countermeasures of XZ rural commercial bank [MSc thesis] (in Chinese). Zhengzhou: Zhengzhou University; 2018.

6. Wei Y. Research on internal control of Shanghai Pudong Development Bank [MSc thesis] (in Chinese). Yunnan: Yunnan University of Finance and Economics; 2020.

7. $\mathrm{Xu} \mathrm{H}$. Analysis on the implementation of internal control in commercial banks (in Chinese). Accountant 2020; (9): 58-59.

8. Teng H. W case study on internal control of small loan business of rural commercial banks (in Chinese). China Academy of Financial Sciences 2019. 